\title{
PENGARUH PELATIHAN KERJA DAN MOTIVASI KERJA TERHADAP KINERJA KARYAWAN PADA PT PRITHO JAKARTA BARAT
}

\author{
${ }^{1 *}$ Dede Andi, ${ }^{2}$ Firhana El Iftiahanis \\ Universitas Pamulang, Tangerang Selatan, Banten, Indonesia \\ 1*dosen02463@unpam.ac.id, 2eliftiahanis@gmail.com
}

\begin{abstract}
Abstrak
Penelitian ini dilakukan dengan bertujuan untuk mengetahui pengaruh pelatihan kerja dan motivasi kerja terhadap kinerja karyawan pada PT Pritho - Jakarta Barat secara simultan. Penelitian ini menggunakan metode kuantitatif. Analisis data menggunakan uji validitas, uji reliabilitas, uji asumsi klasik, analisis regresi, analisis koefisien determinasi dan uji hipotesis. Hasil penelitian ini menunjukkan $\mathrm{R}$ sebesar 0,630 atau 63,0\% yang berarti terdapat hubungan yang positif dan kuat antara pelatihan kerja dan motivasi kerja terhadap kinerja karyawan. Berdasarkan uji hipotesis diperoleh nilai $\mathrm{F}_{\text {hitung }}>F_{\text {tabel }}$ atau $(83,365>3,09)$ dengan demikian $\mathrm{H}_{0}$ ditolak dan $\mathrm{H}_{3}$ diterima. Artinya terdapat pengaruh yang signifikan secara simultan antara pelatihan kerja dan motivasi kerja terhadap kinerja karyawan pada PT Pritho - Jakarta Barat.
\end{abstract}

Kata Kunci: Pelatihan Kerja, Motivasi Kerja dan Kinerja Karyawan

\section{Abstract}

This research was conducted with the aim to find out the influence of job training and work motivation on employee performance at PT Pritho - West Jakarta simultaneously. This research uses quantitative methods. Data analysis uses validity tests, reliability tests, classical assumption tests, regression analysis, determination coefficient analysis and hypothesis tests. The results of this study showed $R$ of 0.630 or $63.0 \%$ which means there is a positive and strong relationship between job training and work motivation to employee performance. Based on the hypothesis test obtained the value of F_hitung > F_tabel or $(83,365>3.09)$ thus $H \_0$ rejected and $H_{-} 3$ accepted. This means that there is a significant simultaneous influence between job training and work motivation on employee performance at PT Pritho - West Jakarta.

Keywords: Job Training, Work Motivation, and Employee Performance

\section{PENDAHULUAN}

Sumber Daya Manusia (SDM) memiliki arti yang sangat penting, hal ini dikarenakan dengan adanya peran aktif dan dominan dari manusia dalam setiap kegiatan organisasi, dimana manusia mempunyai peran sebagai penentu, pelaku bahkan perencana dalam mencapai tujuan perusahaan dan sekaligus menentukan maju mundurnya sebuah perusahaan.

Aspek terpenting dalam keberhasilan organisasi adalah adanya pengelolaan sumber daya manusia, oleh karena itu usaha-usaha untuk mewujudkan tenaga kerja yang berkualitas harus diupayakan yang tidak dapat dilepaskan dari pelatihan kerja dan motivasi kerja bahkan kerjasama tim. Sumber daya manusia yang berkualitas akan dapat dihasilkan jika pengelolaan sumber daya manusia dilakukan dengan baik, dan bisa membentuk kinerja karyawan semakin baik, sehingga bisa berdampak positif pada efektivitas kinerja didalam perusahaan secara keseluruhan.

Pelatihan merupakan salah satu upaya untuk meningkatkan kemampuan, baik individu maupun kelompok agar dapat memberikan sumbangan kepada efektivitas dan efisiensi organisasi, dimana melalui kemampuan, baik pengetahuan dan keterampilan karyawan yang memadai dan sesuai dengan bidang tugas akan dapat memberikan kontribusi kepada peningkatan efisiensi dan efektivitas organisasi dalam mencapai tujuan dan sasarannya. Akan tetapi apabila karyawan 
tidak atau kurang memiliki kemampuan dalam pengetahuan dan ketrampilan, selain akan menjadi beban organisasi, juga akan menjadikan organisasi tersebut kurang efektif dan efisien dalam mencapai tujuan yang telah ditetapkan.

Disamping pelatihan kerja, Motivasi pun dibutuhkan untuk menunjang keberhasilan suatu perusahaan dalam mencapai tujuannya. Sebab melalui motivasi akan menciptakan tingkat kinerja yang tinggi sehingga dapat menunjang keberhasilan perusahaan. Sebaliknya jika tingkat kinerja menurun akan menghambat perusahaan tersebut mencapai tujuan.

Motivasi merupakan perangsang bagi karyawan agar bisa bekerja lebih baik, dan bisa mendorong karyawan untuk lebih giat lagi dalam bekerja dan lebih bergairah, sehingga akan menguntungkan perusahaan. Motivasi itu sendiri merupakan salah satu faktor yang dapat mempengaruhi kinerja karyawan dalam perusahaan, dan merupakan faktor yang menggerakkan seseorang untuk mempunyai keinginan dan kesediaan bekerja. Bahkan bagi karyawan yang termotivasi dalam melaksanakan pekerjaannya, mempunyai anggapan bahwa tugas mereka merupakan tantangan yang harus diselesaikan, dan mereka akan mengerahkan seluruh kemampuan yang mereka miliki untuk menyelesaikan pekerjaan secara antusias, dan bagi karyawan yang tidak termotivasi, maka kinerjanya tidak dapat maksimal dan tujuan perusahaan tidak dapat tercapai.

\section{TINJAUAN PUSTAKA}

\section{Pelatihan Kerja}

Pelatihan kerja menurut

Sedarmayanti (2013:198) “Sebagai sarana yang ditunjukkan pada upaya untuk lebih mmengaktifkan kerja para anggota organisasi yang kurang aktif sebelumnya, mengurangi dampakdampak negatif yang dikarenakan kurangnya pendidikan, pengalaman yang terbatas, atau kurangnya kepercayaan diri dari anggota atau kelompok anggota tertentu.

\section{Motivasi}

Menurut Hasibuan Melayu S.P (2012:191) "Motivasi adalah suatu perangsang keinginan daya gerak kemauan bekerja seseorang, setiap motif mempunyai tujuan tertentu yang ingin dicapai".

\section{Kinerja}

Menurut Mangkunegara (2017:67) “Kinerja adalah hasil kerja secara kualitas dan kuantitas yang dicapai oleh seorang pegawai dalam melaksanakan tugasnya sesuai dengan tanggung jawab yang diberikan kepadanya.

Dengan demikian, dapat disimpulkan bahwa kinerja merupakan proses pencapaian tujuan organisasi dari usaha sumber daya manusia itu sendiri melalui sebuah proses kerja secara kualitas dan kuantitas dalam melaksanakan tanggung jawabnya.

\section{METODE}

Jenis penelitian ini adalah kuantitatif asosiatif, menurut Sugiyono (2017:44) yaitu "penelitian asosiatif bertujuan untuk mengetahui pengaruh atau hubungan antara dua variabel atau lebih". Dengan demikian penelitian asosiatif ini dapat dibangun suatu teori yang berfungsi untuk menjelaskan, meramalkan dan mengontrol suatu gejala. Penelitian ini merupakan studi empiris yang bertujuan untuk menguji pengaruh pelatihan kerja dan motivasi kerja terhadap kinerja karyawan. Dalam penelitian ini populasinya adalah karyawan PT Pritho - Jakarta Barat dengan jumlah karyawan sebanyak 135 orang. Sampel dalan penelitian 101 responden.

\section{KESIMPULAN DAN SARAN Kesimpulan}

Berdasarkan penelitian yang telah dilakukan serta diuraikan oleh penulis pada bab IV mengenai pengaruh pelatihan kerja dan motivasi kerja terhadap kinerja karyawan PT Pritho - Jakarta Barat maka dapat disimpulkan sebagai berikut:

1. Terdapat pengaruh antara pelatihan kerja terhadap kinerja karyawan pada PT Pritho - Jakarta Barat, hal tersebut 
dibuktikan dengan hasil uji regresi linier sederhana dengan rumus $\mathrm{Y}=\mathrm{a}+\mathrm{b}_{1} \mathrm{X}_{1}$ dengan hasil $Y=10,210+0,752 X_{1}$. Berdasarkan hasil uji $\mathrm{t}$ antara variabel pelatihan kerja dan kinerja karyawan didapatkan nilai $t_{\text {hitung }}>t_{\text {tabel }}(11,996>$ 1.98422). Dan berdasarkan koefisien determinasi diketahui bahwa nilai $R$ Square $\left(\mathrm{r}^{2}\right)$ sebesar 0,592 atau 59,2\%. Jadi dapat disimpulkan bahwa pelatihan kerja mempengaruhi kinerja karyawan sebesar 59,2\%. Sedangkan sisanya sebesar 0,408 atau 40,8\% dipengaruhi oleh faktor lain yang tidak digunakan dalam penelitian ini.

2. Terdapat pengaruh antara motivasi kerja terhadap kinerja karyawan pada PT Pritho - Jakarta Barat, hal tersebut dibuktikan dengan hasil uji regresi linier sederhana dengan rumus $\mathrm{Y}=\mathrm{a}+\mathrm{b}_{2} \mathrm{X}_{2}$ dengan hasil $Y=15,839+0,616 \mathrm{X}_{2}$. Berdasarkan hasil uji $t$ antara variabel motivasi kerja dan kinerja karyawan didapatkan nilai $t_{\text {hitung }}>t_{\text {tabel }}(8,572>$ 1.98422)Dan berdasarkan koefisien determinasi diketahui bahwa nilai $R$ Square $\left(\mathrm{r}^{2}\right)$ sebesar 0,426 atau $42,6 \%$. Jadi dapat disimpulkan bahwa motivasi kerja mempengaruhi kinerja karyawan sebesar 42,6\%. Sedangnya sisanya sebesar 0,574 atau 57,4\% dipengaruhi oleh faktor lain yang tidak digunakan dalam penelitian ini.

3. Terdapat pengaruh secara bersama-sama antara pelatihan kerja dan motivasi kerja terhadap kinerja karyawan pada PT Pritho dengan uji regresi linier berganda dengan rumus $\mathrm{Y}=\mathrm{b}_{1} \mathrm{X}_{1}+\mathrm{b}_{2} \mathrm{X}_{2}$ dengan hasil $Y=7,146+0,586 X_{1}+0,242 X_{2}$. Berdasarkan hasil uji $\mathrm{F}$ dimana nilai $\mathrm{F}_{\text {hitung }}>F_{\text {tabel }}(83,365>3,09)$. Dengan nilai koefisien determinasi $\left(r^{2}\right)$ yang diperoleh sebesar 0,630 atau $63,0 \%$. Sedangkan sisanya sebesar 0,370 atau $37,0 \%$ disebabkan oleh faktor lain yang tidak diteliti dalam penelitian ini.

\section{Saran}

Berdasarkan kesimpulan hasil penelitian mengenai pengaruh pelatihan kerja dan motivasi kerja terhadap kinerja karyawan pada PT Pritho peneliti mengajukan saran yang dapat dijadikan solusi dari pembahasan dan dapat dijadikan sebagai bahan pertimbangan bagi manajemen perusahaan dalam mengambil kebijakan manajemennya.

1. Dari hasil pengolahan variabel $X_{1}$ (pelatihan kerja) yang didapat, hasil terendah dari para responden terdapat pada indikator tujuan pelatihan dengan pernyataan setelah mengikuti pelatihan saya mampu menyelesaikan pekerjaan dengan lebih mudah dan cepat. Artinya program pelatihan yang dilakuan oleh perusahaan harus tepat sasaran dan tujuan dari pelatihan yang dilakukan mempunyai manfaat bagi karyawan yang mengikuti pelatihan.

2. Dari hasil pengolahan variabel $X_{2}$ (motivasi kerja) yang didapat, hasil terendah dari para responden terdapat pada indikator kebutuhan penghargaan dengan pernyataan perusahaan selalu memuji atas hasil kerja karyawan. Artinya PT Pritho harus lebih mengapresiasi kinerja karyawannya salah satunya yaitu dengan cara memberikan pujian atas hasil kerjanya karena sekecil apapun pujian dari atasan dapat menambah semangat kerja karyawan.

3. Dari hasil pengolahan variabel Y (kinerja karyawan) yang didapat, hasil terendah dari para responden terdapat pada indikator kuantitas kerja dengan pernyataan dalam menyelesaikan tugas saya selalu berusaha menyelesaikannya dengan cepat. Oleh karena itu sebaiknya karyawan harus lebih bertanggung jawab atas pekerjaan yang diberikan serta lebih meningkatkan kecepatan dan ketepatan waktu dalam bekerja sehingga pekerjaan tersebut dapat terselesaikan dengan tepat waktu demi mencapai target yang ditentukan perusahaan.

4. Untuk peneliti selanjutnya agar menggunakan variabel lain selain pelatihan kerja, motivasi kerja dan kinerja karyawan agar bisa membantu perusahaan untuk bisa lebih berkembang lagi. 
DAFTAR PUSTAKA

Abdullah, M. 2014. Manajemen dan Evaluasi Kinerja Karyawan. Yogyakarta : Penerbit Aswaja Pressindo.

Abdullah, M. Ma'ruf, "Manajemen dan Evaluasi Kinerja Karyawan", Aswara Pressindo, Jakarta 2014

Abraham H. Maslow dalam Sutrisno (2017) Teori Hirarki Motivasi, Rajawali, Jakarta.

Affandi, A., et al. (2020). Optimization of MSMEs Empowerment in Facing Competition in the Global Market during the COVID-19 Pandemic Time. Systematic Reviews in Pharmacy, 11(11), 1506-1515.

Akhmad Subekhi dan Mohamad Jauhar, 2012. Pengantar Teori dan Perilaku Organisasi". Bandung: PT. Remaja Rosdakarya

Algifari. (2014). "Analisis Regresi, Teori, Kasus \& Solusi". Yogyakarta: BFFE UGM.

Ardana, 2012, Manajemen Sumber Daya Manusia, Graha Ilmu, Yogyakarta.

Debby Endayani Safitri. Jurnal Ekonomi dan Bisnis (2019). ISSN: 2085-9996. Vol.8, No.2, Hal.240-248. "Pengaruh pelatihan kerja terhadap kinerja karyawan pada PT. Batam".

Dessler, Gary. 2015. Manajemen Sumber Daya Manusia.diterjemahkan oleh Diana Angelica, Edisi ke Empat Belas, Salemba Empat, Jakarta.

Eko Widodo, Suparno.2015." Manajemen Pengembangan Sumber Daya Manusia".Yogyakarta: Pustaka Pelajar

Fernanda M.B Tuhumena. Jurnal EMBA (2019). ISSN: 2303-1174. Vol.5, No.2. Hal.1-9. "Pengaruh pelatihan dan motivasi kerja terhadap kinerja karyawan pada PT. Pegadaian (persero) kantor wilayah $v$ manado".

Ghozali, Imam. 2017. Aplikasi Analisis Multivariete Dengan Program IBM SPSS (Edisi 8). Cetakan ke VIII. Semarang : Badan Penerbit Universitas Diponegoro.
Hasibuan, Melayu. (2017). Manajemen Sumber Daya Manusia Edisi Revisi. Jakarta: PT Bumi Aksara.

Hermawati, R., et al. (2020). The Effect of Trilogy Leadership Style and Organization Culture on School Performance: Evidence form Indonesian Senior High School. PalArch's Journal of Archaeology of Egypt/Egyptology, 17(6), 85128537.Fdisiplin

Mahpudin. Jurnal Edunomic (2018). ISSN: 2451-5621. Vol.6, No.2, Hal.86-99. "Pengaruh motivasi kerja terhadap kinerja karyawan pada PT. Bank Central Asia, Tbk Cabang Karawang".

Malayu S.P Hasibuan, 2017, Manajemen Sumber Daya Manusia, Jakarta: PT Bumi Aksara

Mc. Clelland, Edward Murray, Miller dan Gordon W, dan Anwar Prabu Mangkunegara (dalam Anwar Prabu Mangkunegara, 2014:76) Pengaruh Motivasi Berprestasi terhadap Kinerja Karyawan

Moeheriono. (2012). "Pengukuran Kinerja Berbasis Kopetensi". Jakarta: Raja Garafindo Persada.

N. Lilis Suryani, Kiki Zakiah. Jurnal ilmiah manajemen Sumber Daya Manusia (2019). ISSN: 3369-6865. Vol. 3, No. 1, Hal. 73-84. "Pengaruh Pelatihan dan Disiplin Kerja terhadap kinerja pada PT. Bank Negara Indonesia BSD Tanggerang".

Nur Rahmah Andayani. Jurnal Akuntansi, Ekonomi dan Manajemen (2016). ISSN: 2337-7887. Vol.4, No.1, Hal.4146. "Pengaruh pelatihan kerja dan motivasi kerja terhadap kinerja karyawan bagian PT. PCI Elektronik International".

Nuridha Citraningsyas, Indi Djastuti, Diponegoro Journal of Management (2017). ISSN: 2337-3792. Vol. 6, No. 4, Hal 1-11. "Pengaruh Pelatihan dan Lingkungan Kerja terhadap Kinerja Karyawan dengan Kepuasan Kerja sebagai Variabel Intravening"

Nurjaya, N., et al. (2021). Pengaruh Kompetensi Sumber Daya Manusia 
Dan Kemampuan Pemanfaatan Teknologi Terhadap Kinerja Aparatur Desa Pada Kantor Kepala Desa Di Kabupaten Gunungkidul, Yogyakarta. JENIUS (Jurnal Ilmiah Manajemen Sumber Daya Manusia), 4(3), 332-346.

(2021). Pengaruh Etos

Kerja Dan Disiplin Kerja Terhadap Kinerja Pegawai Pada Dinas Kehutanan Dan Perkebunan Kota Bogor. JENIUS (Jurnal Ilmiah Manajemen Sumber Daya Manusia), $4(2), 172-184$.

Pawar, A., et al. (2020). Organizational Servant Leadership. International Journal of Educational Administration, Management, and Leadership, 63-76.

Rivai Zainal, Veithzal.2015. Manajemen Sumber Daya Manusia untuk Perusahaan dari Teori ke Praktik, Jakarta:PT Raja Grafindo Persada.

Rizal Dwi Prasetyo, E-Proceesing of Management. Desember (2016) ISSN: 2355-9357. Vol. 3, No. 3. Hal. 114-123. "Pengaruh Motivasi terhadap Kinerja Karyawan pada PT. Semen Padang Biro Pekerjaan Umum".

Safroni, Ladzi. 2015. Manajemen dan Reformasi Pelayanan Publik dalam Konteks Birokrasi Indonesia, Aditya Media Publishing, Surabaya

Santoso, Singgih. 2015. Menguasai Statistik Non Parametik: Konsep Dasar dan Aplikasi dengan SPSS. Jakarta: Elex Media Komputindo

Sedarmayanti. 2016. Manajemen Sumber Daya Manusia Reformasi Birokrasi Dan Manajemen Pegawai Negeri Sipil. Bandung: PT. Refika Aditama.

Setyowati Subroto. Jurnal ekonomi dan kewirausahaan (2018). ISSN: 19782586. Vol. 12, No. 1. Hal. 69-81. "Pengaruh Pelatihan dan Motivasi terhadap Kinerja Karyawan pada PT. Trias Sentosa, krian Sidoarjo".

Siregar, Syofian. 2015. Statistik Parametrik Untuk Penelitian Kuantitatif Dilengkapi dengan Perhitungan Manual dan Aplikasi SPSS Versi 17. Jakarta: PT. Bumi Aksara.
Sudjana, Nana. (2013). Penilaian hasil belajar mengajar. Bandung: PT Remaja Rosdayakarya.

Sugiyono. (2017). "Metode Penelitian Pendidikan Pendekatan Kuantitatif, Kualitatif dan R\&D". Bandung: Alfabeta

Suherman, Wawan (2015) “Kurikulum Berbasis Kompetensi Pendidikan Jasmani Teori dan Praktik Pengembangan", Yogyakarta: FIK UNY.

Sunarsi, D. (2018). Pengaruh rekrutmen, seleksi dan pelatihan terhadap produktivitas kerja karyawan. KREATIF: Jurnal Ilmiah Prodi Manajemen Universitas Pamulang, 6(1), 14-31.

Sunarsi, D., Wijoyo, H., Prasada, D., \& Andi, D. (2020, September). Pengaruh lingkungan kerja terhadap kinerja karyawan pada pt. Mentari persada di jakarta. In Seminar Nasional Manajemen, Ekonomi, Akuntansi (Vol. 5, No. 1, pp. 117-123).

Sunyoto, Danang. 2013. Teori, Kuisioner, dan Analisis Data Sumber Daya Manusia (Praktik dan Penelitian). CAPS : Yogyakarta

Vincent Intan, Jurnal Sultanist. Juni (2015). ISSN: 2338-4328. Vol. 3, No.1. Hal. 8793. "Pengaruh Pelatihan terhadap Kinerja Karyawan pada PT. Permata Niaga Cabang Pematang Siantar".

Wilandari, D. F., Sunarsi, D., \& Mas'adi, M. (2021). Pengaruh Penilaian Kerja Terhadap Kinerja Karyawan Pada PT. Jaya Mandiri Rekabuana di Cilandak. Jurnal Ekonomi Efektif, 3(2).

Yusnita. Jurnal Ilmiah Manajemen Fakultas Ekonomi (2018). ISSN: 2502-5678. Vol.1, No.1, Hal.41-46. "Pengaruh pelatihan terhadap kinerja karyawan pada CV Cibalung Happy Land Bogor". 